Article

\title{
Users' Perception of Value of Travel Time and Value of Ridesharing Impacts on Europeans' Ridesharing Participation Intention: A Case Study Based on MoTiV European-Wide Mobility and Behavioral Pattern Dataset
}

\author{
Eva Malichová *(1), Ghadir Pourhashem * (D), Tatiana Kováčiková and Martin Hudák \\ Department of International Research Projects-ERAdiate+, University of Žilina, 01026 Žilina, Slovakia; \\ Tatiana.Kovacikova@erachair.uniza.sk (T.K.); Martin.Hudak@erachair.uniza.sk (M.H.) \\ * Correspondence: eva.malichova@fri.uniza.sk (E.M.); ghadir.pourhashem@erachair.uniza.sk (G.P.)
}

Received: 17 March 2020; Accepted: 15 May 2020; Published: 18 May 2020

\begin{abstract}
Ridesharing as a form of mobility service increased significantly and has become a popular concept in recent years among users, mobility authorities, and transport service providers. This research focused on exploring an emerging view of value of travel time (VTT) from the traveler's perspective, based on the stated travel time worthwhileness, preferences and motivations on their intention towards participation in ridesharing to evaluate individual's perception of VTT and perceived value of ridesharing (VRS) impacts on intentions to participate in car sharing for their daily commuting using multinomial logit (MNL) model. This is particularly relevant today, as peer-to-peer mobility services are on the one hand shaping and redefining the value of technologies, and services, and on the other hand introducing new actors in the mobility eco-system. This study describes a survey of 278 people in 4 European countries: Finland, Portugal, Spain, and Slovakia as part of the "Mobility and Time Value" (MoTiV) H2020 project EU-wide data collection. In short, the empirical analysis indicates the high significance of enjoyment in terms of travel time worthwhileness on ridesharing adoption for commuting trips. Results also revealed economic benefit and enjoyment of being social as major motivators for participation in ridesharing. Findings are discussed in terms of implications for urban and transport planners, policy makers, and authorities to implement in shared mobility planning and to prepare transport policies which are tailored to individuals' ridesharing needs and travel preferences and count also on travel happiness factors to better reflect the traveler's personal ambitions. Suggestions for future research on shared mobility planning are outlined in conclusion.
\end{abstract}

Keywords: travel time worthwhileness; travel preferences; perceived value of ridesharing; ridesharing intention; mobility planning; transport policy

\section{Introduction}

The shared economy is currently getting to the foreground in terms of its scope as well as its penetration into all aspects of social and economic life [1]. Nowadays, people's interest in ownership itself is decreasing, while they are rather oriented on the efficient utilization of the things available for the achievement of a certain benefit. For consumers, it is more convenient and cheaper to rent or borrow things rather than owning them. Such utilization of the capacity in everyday life can bring a considerable decrease in the demand for the products, affect the degree of their utilization and contribute to sustainability and saving of money, as well as human and unrenewable resources [2]. 
Transport is a sector which is an inextricable part of the shared economy. Based on the survey focused on the use of collaborative economy from 2018, people in the European Union were using collaborative apps mainly for accommodation services and transport [3]. Shared transport is an innovative transport concept whose objective is the maximization of the mobility resources' utilization [4]. Thus, it represents short-term access to any shared means of transport based on the user's needs, usually via the use of a smartphone-based application [4-6]. The basic forms of shared mobility include services—such as ridesharing, bike-sharing, car sharing, and scooter-sharing-that can be categorized as a part of passenger shared transport. This has been experiencing rapid development especially in larger cities in recent years. This expansion can paradoxically be caused by the increasing number of passenger cars. Based on the information from Eurostat from 2017, it can be observed that the number of passenger cars was rising annually almost in all countries of the European Union since 2013, in some of them the increase was by up to 18\% [7]. Such an increase in the number of automobiles can cause serious problems in transport such as traffic congestion and parking problems, especially in large cities, which can be one of the reasons for using shared transport.

Apart from the rising number of passenger cars, the expansion and the utilization of shared transport were also influenced by the launch of new technologies into everyday life. The affordability of mobile devices and the emergence of mobile applications considerably facilitated the access of people to shared services, which stimulated their development [8]. However, based on the survey carried out in the states of the European Union, the biggest reason for not using collaborative platforms is still the fact that people do not know about them [3]. The use of smartphone applications, besides providing a tailored service to citizens, can also contribute to promoting participatory mobility planning. For instance, volunteer groups in greece could provide continuous monitoring of the phenomenon at city level by participation in a crowdsourcing data collection that could give a chance of quick evaluation of interventions to produce measurable results and to adopt corresponding practices [9]. The crowdsourcing concept is currently used mainly in sectors such as politics, business, and entertainment; however, in near future, it could be used more often in transport to identify individual travelers' preferences and support behavioral change in transport in particulare modal shift [10].

Nowdays, an important aspect affecting the development of shared transport is represented by the changing preferences of the consumers. Mainly among young people, a change in the attitude to individual ownership can be observed, which is followed by the support of shared activities, in this case, shared transport. A substantial criterion in the selection of the means of transport is currently becoming represented by their impact on the environment. People are trying to use more ecological forms of transport and lower their carbon footprint. From the perspective of ecology, shared transport contributes to decreasing in negative impacts on the environment and to sustainability of transport. Other aspects considerably influencing the development of shared transport include the economic as well as the social aspect.

The use of forms of shared mobility brings advantages not only to the users of these services but also to the whole society. Even though the use of shared transport services is rising, it still does not reach the values that would bring a significant change, affecting the sustainability of transport and mitigating veritable scourge of transport on the environment. Gaining knowledge of the attitudes and opinions of people on shared transport, identification of its substantial advantages and disadvantages and the elimination of these disadvantages can significantly contribute to the improvement of these services, to their adoption among broader groups of people, and to travel behavior change.

Despite the fact that many research studies have been accomplished in this field, there has been little attention paid to exploring the influence of individuals' perception of VTT beyond the time and cost saving [11,12] on ridesharing choice. The perceived value proposition of a certain travel option may not match the actual value delivered to the traveler. When the actual experience has a lower value than the perceived one, this could affect future mobility choices towards the use of other transport modes in similar situations. Knowledge on barriers and factors playing a role in the traveler's choice is therefore 
key to aligning expectations and actual experience. The conception, development, and deployment of mobility infrastructure, services, and solutions from the perspective of individual motivations, needs and expectations defines and shapes a value proposition of mobility (VPM). This represents a promise of value to be delivered, communicated, and acknowledged to the individual traveler. Groups of travelers with similar needs, aspirations, motivations, and expectations are likely to also have a similar general judgment for different transport options. In this respect, which values and expectations should be generally fulfilled and therefore addressed by mobility solutions?

The MoTiV project aims at reducing this knowledge gap by addressing emerging views and perspectives on VTT and adopting the travelers' viewpoint. In this respect, it does not only focus on the economic value of travel time savings, which is central to VTT studies carried out since the 1960s to support transport appraisals. Rather, it adopts a broader conceptual framework that attempts to quantify how endogenous and exogenous factors shape the individual travel experience for various trip purposes, thus contributing to the sense of 'wasted' or 'worthwhile' travel time and achieving a broader and more interdisciplinary conceptualization. Ridesharing, as an early and typical form of mobility solution [13], was selected in this study because it can also be considered a new form of car culture since in many cases it is about sharing a ride with the family members, friends, or colleagues.

The current research focuses on expanding the scope of ridesharing incorporating individuals' perception of VTT, perceived VRS, and personal attitudes towards ridesharing and socio-demographic attributes to investigate factors influencing travel makers' intention towards adoption of ridesharing services. In our study, by ridesharing we mean peer-to peer services (i.e., carpooling and ridesharing services) for a particular trip used by research participants [14,15]. In addition, the results from this study also provide insights on ridesharing intention for different types of city according to OECD classification of functional urban areas. These factors will be analyzed thanks to a European-wide mobility and behavioral pattern dataset was collected through the Woorti App during the MoTiV project.

The paper is structured in six sections. Section 2 provides an overview of ridesharing. The literature review in this section focuses on state-of-the-art. Section 3 presents methodological framework, the data collection and sample description. Section 4 presents firstly statistical descriptions of the of perceived VTT and VRS and socio-demographic characteristics of the sample for empirical investigation and model development. Then the results of the model estimation within the scope of the econometric modeling analysis are presented. These results are discussed in Section 5. Finally, Section 6 concludes by summarizing the results of the research, its contribution and further suggestion for future studies.

\section{Literature Review}

This section is focused on the definition of ridesharing as we understand it in the research and on the analysis of the previous research projects concerning the attitudes towards ridesharing. Ridesharing, also called carpooling and car sharing, is an alternative way of transportation. There are several definitions for ridesharing in literature since the inception of ridesharing. However, these definitions have certain common features. In general, ridesharing can be considered a type of transport in which the means of transport is used at least by two persons who commute to the same destination or travel in the same direction [16-21]. These rides are either arranged beforehand or they change on a daily basis according to changing requirements [22]. Ridesharing is mostly used for rides to work or school [23], but it is also used for the trips related to taking children from/to school, personal and leisure activities and shopping [24]. A considerable difference in the definitions occurs in the defining of passengers and the profitability related to this aspect.

Some scholars consider ridesharing to be nonprofit [20] and informal to some extent [17]. In this case, the profit is not the primary purpose; however, the costs related to the ride realised (e.g., fuel costs, parking expenses, and tolls) can, but do not have to be, shared among the passengers $[15,16,20]$. In this definition of ridesharing, the passengers mainly include people who know each other and belong into the same social network, namely the members of a household, family members, friends, and colleagues $[17,25]$. On the other hand, there are scholars who exclude family members from 
ridesharing $[21,26]$ and consider ridesharing to be rather a public or private service which is chargeable (for profit rides) [16]. Commercial ridesharing represents a situation in which the customer requests a ride in a private vehicle via a smartphone or web application being administered by a ridesharing company. In this case, ridesharing can also be noted as ride-sourcing, a vehicle for hire, paratransit [27], or an on-demand ride service $[28,29]$.

Within the needs of our research, we consider ridesharing to be a type of transportation in which a private vehicle is being shared by at least two people regardless of their mutual relationship, with the purpose of traveling in the same direction or to the same destination, without the orientation of profit-making.

The use of ridesharing brings a number of advantages. Apart from being recognized as a simple and relatively financially undemanding way of transport, it is also considered to be a solution for the traffic jams since it lowers the number of cars on the roads, which is followed by the reduction of emissions and noise and thus the reduction of harmful impacts on the environment, negative externalities, and the support of sustainability of natural resources [30-34]. In addition, ridesharing broadens the possibilities for traveling long distances [35,36], lowers the transportation costs, saves time and parking spaces, and it also has an influence on decreasing car accidents [32,33].

To achieve these advantages mostly focused on the mitigation of adverse impact on environment, it is necessary to know the attitudes and motivational factors behind people's decision on using ridesharing services.

There are several studies in which the authors focused on the identification of people's attitudes towards ridesharing, identification of factors influencing the use of ridesharing, as well as on the willingness to share one's ride $[21,24,37,38]$. The assumption is that the individuals who have positive opinions about ridesharing are willing to use it more and vice versa [17]. However, based on the research conducted by Ciari [21], it can be observed that even though $78 \%$ of respondents expressed their positive opinion about ridesharing, only half of them were actually willing to share their rides. Therefore, there is considerable space for future improvement and increase in the utilization of such services.

Noah et al. [39] defined four groups of factors influencing the decision-making of an individual on the use of ridesharing, which are divided based on them being internal or external to the commuter. Internal factors are focused on individual characteristics of each commuter and judgemental factors (commuter's reason to rideshare), and external factors are related to situational factors and interventions.

\subsection{Internal Factors}

A group of important factors influencing the decision-making on the use of ridesharing is represented by psychological factors, also called judgmental factors. These include attitudes and preferences of people related to commuting itself, privacy, comfort, social interaction, or the protection of the environment [40]. We consider one of the most substantial reasons for the use of ridesharing to be the relationship of people to the protection of the environment and to the reduction of negative impacts on the environment. In the research projects dealing with the attitudes of people towards ridesharing in Switzerland [21] and France [24], the protection of the environment belonged to the most frequently chosen reasons for the use of this type of transportation. In the present world where the pressure is constantly being put on the sustainability, utilization of this type of transportation is a huge positive and it can be labeled as ecologically sustainable [17]. Its more ecological nature can be a considerable motivator for the people who care for the environment's protection. The people who are trying to protect the environment and know that ridesharing is a more sustainable form of transportation than the commuting by car itself prefer its use [37]. Besides the environment's protection, other important motivators for the use of ridesharing include socialization and costs saving, or the reduction of the occurrence of traffic congestions [24]. This group also includes the preferences of a commuter regarding the driver. Based on the Ciari's [21] research, it was revealed that the respondents considered the driving style and the appearance of the driver and whether she/he was a non-smoker as 
the most important features. On the other hand, the gender and the age of the driver were considered the least important features.

Despite the considerable attention given to the subjective attitudinal factors influencing individuals' ridesharing behavior in many urban areas, VTT in relation to the value proposition of mobility is still an underresearched area, which affects not only the ridesharing travel behavior itself but also the travel preparation and personal schedules. To our knowledge, there is no existing research approaching mobility and ridesharing that takes into account value proposition of mobility (happiness/satisfaction) for travel choice.

The other group of internal factors are the social-demographic characteristics such as age, sex, income, and marital status. However, the opinions of different authors regarding these factors vary. Based on some researches, the social-demographic factors can be considered negligible, not having a considerable impact on the selection of the transportation mode $[38,40]$. Based on other studies, it can be stated that women use ridesharing more than men [41] and also that younger people use ridesharing more than the older people. Payyanadan and Lee [16] carried out a research focused on the understanding of ridesharing needs of older people in which they found out that these people prefer to share a ride with their families and friends, which is related to the security and elimination of communication problems during the arranging of the place and time for a pickup and a drop-off. Their most frequent worries included the use of a tool for ridesharing, reliability, communication, and privacy. These factors can also include the possession and number of cars in a household. However, the researches differ in this case. While Zhang and Zhang [41] in their research revealed that the possession of a car significantly negatively affects the frequency and probability of using ridesharing. Yu et al. [36] contrarily state that ridesharing is more attractive for car owners since it lowers transportation costs and eliminates problems with parking. However, these findings are affected by the locality in which the respondents lived. Thus, some social-demographic factors can considerably contribute to the prediction of ridesharing users' behavior [42].

\subsection{External Factors}

The external factors consist of situational factors and interventions. The accessibility of public transport can be considered the most important situational factor. The popularity of ridesharing is high if the accessibility of public transport is low. Another important factor is the price of fuel and the transport costs related to it. If the price of fuel increases, people use ridesharing more and reduce private transportation. The commute time and the distance to the target destination are also substantial factors in the use of ridesharing. In the majority of cases, the distance to work is being stated, but ridesharing is also widely used for commuting to school, going shopping, and for personal leisure time activities [23,24]. This group can also include the factors such as the size of the employer company that can affect the possibility and the number of potential passengers, population density, or the time spent waiting for a shared ride [39].

The last group of factors is represented by interventions. These are needed for the increase in the awareness of ridesharing, elimination of prejudices, provision of benefits for the people using these services, and increasing the popularity of ridesharing and its utilization itself. One of the main reasons for not using ridesharing is an insufficient level of information on such services and platforms $[3,43]$. Thus, as a start, it is necessary to make this service more visible, e.g., via the people already using ridesharing. If a person's friends, acquaintances, or colleagues use this service, it is probable that the person will start using it too [37]. Apart from the conventional benefits of ridesharing such as sharing the costs and socialization, other stimuli are needed to encourage the use of ridesharing. These stimuli can be positive as well as negative. The positive ones include the decrease of parking fee, reserved or free parking for people using ridesharing, high-occupancy vehicle lanes, reward programs, partner-matching programs, and a guaranteed ride home. Such stimuli do not only have to be provided by the companies operating the platforms for ridesharing or the policymakers but also, for example, by the employers. The accessibility of this service at work can significantly increase its usage [38]. 
All factors influencing the decision-making of an individual on the use of ridesharing are summarized in Table 1.

Table 1. Factors influencing the decision-making of an individual on use of ridesharing.

\begin{tabular}{|c|c|c|}
\hline \multicolumn{3}{|c|}{ Factors Influencing the Decision-Making on the Use of Ridesharing } \\
\hline \multirow{2}{*}{ Internal Factors } & Psychological factors & $\begin{array}{c}\text { Attitudes and preferences related to commuting } \\
\text { Attitudes and preferences related to privacy } \\
\text { Attitudes and preferences related to comfort } \\
\text { Attitudes and preferences related to social interaction } \\
\text { Attitudes and preferences related to protection of the environment } \\
\text { Preferences of a commuter regarding the driver }\end{array}$ \\
\hline & $\begin{array}{l}\text { Social-demographic } \\
\text { characteristics }\end{array}$ & $\begin{array}{c}\text { Age } \\
\text { Sex } \\
\text { Income } \\
\text { Marital status } \\
\text { Number of cars in household } \\
\text { Possession }\end{array}$ \\
\hline \multirow[t]{2}{*}{ External Factors } & Situational factors & $\begin{array}{l}\text { Accessibility of public transport } \\
\text { Price of fuel/transport costs } \\
\text { Commute time } \\
\text { Distance to the target destination } \\
\text { Size of the employer company } \\
\text { Population density } \\
\text { Time spent waiting for a shared ride }\end{array}$ \\
\hline & Interventions & $\begin{array}{c}\text { Parking discounts } \\
\text { HOV lanes } \\
\text { Reward programs } \\
\text { Partner-matching programs } \\
\text { Guaranteed ride home }\end{array}$ \\
\hline
\end{tabular}

This research focus is to identify how individuals' subjective travel experience (e.g., perception of value of travel time (VTT) and value of ridesharing (VRS)) influence their choice of ridesharing during daily commuting as depicted in Figure 1:

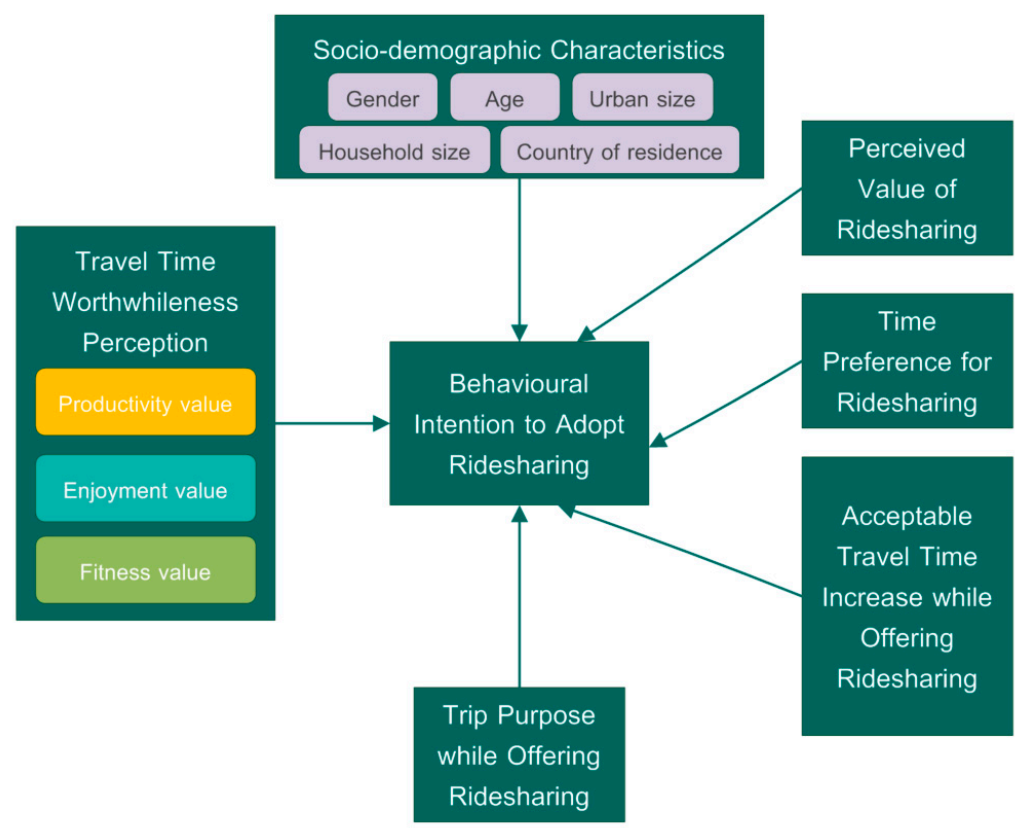

Figure 1. Proposed model for explaining behavioral intention towards ridesharing. 


\section{Research Method}

\subsection{Data Collection and Sample Description}

The data used in this paper were collected through a ridesharing stated preference (SP) survey within the H2020 MoTiV data collection campaign that was conducted in two phases between May and December 2019. The overall target of the MoTiV project was to collect data from at least 4000 users using MoTiV App (Woorti) for 14 days in 8 European countries. The Woorti app was developed by project partners to collect mobility data from European travelers and their subjective assessments on use and valuation of travel time. Specifically, the collected data includes: traveler (user) profile: socio-demographic details, transport preferences, and attitudes towards travel time; trip data: origin/destination, travel time, travel distance, modes of transport, travel purpose; traveler's contextual assessment of worthwhile travel: traveler's trip rating in terms of worthwhileness, details on type of value (e.g., productivity, enjoyment, fitness), and activities carried out during the trip; contextual experience factors: individual assessments on how features of the transport system (e.g., infrastructure, services, external conditions such as weather) influence mobility choices and perceived time value and mobility behavior statistics: aggregated information regarding personal travel behavior (e.g., travel time, travel distance, overall trip worthwhileness, most common activities, carbon footprint); and comparison of the statistics to users in the same community. This dataset will be accessible via the MoTiV project website and relevant Open Data repositories.

The ridesharing data as a complementary part of MoTiV European-wide data collection was executed between October and December 2019 in four European countries: Finland, Portugal, Spain, and Slovakia. The survey covered $10 \%$ of Woorti users who had been selected randomly.

Participants were asked to answer questions regarding ridesharing intention, perception on value of ridesharing (i.e., financial benefit, time benefit, helping or meeting new people, environment concerns, good reputation), time preference for ridesharing, acceptable travel time increase while offering ridesharing, trip purpose while offering ridesharing.

Furthermore, the socio-demographic characteristics of Woorti users and their perception of travel worthwhileness (i.e., the subjective experience of travel time) for three core values: productivity, enjoyment, and fitness and data on the traveler mobility were inquired through questions asked at onboarding when the users opened the Woorti app for the first time. For the survey, 717 people were approached to fill the questionnaire sent through Woorti. After a cleaning and screening procedure, the sample was reduced to 278 persons among them 150 (54.2\%) females and 127 (45.8\%) males.

Regarding the age, the overall sample is slightly skewed towards the 16-49-year-old population. This was largely explained by the design of Woorti app which tended to be more appealing to these groups. In terms of urban size, more than half of the respondents (52\%) are from small towns with up to 100,000 inhabitants. $11 \%$ of respondents live in medium sized cities with population up to 500,000 inhabitants and $37 \%$ are inhabitants of metropolitan areas (see Figure 2). Most of respondents also reported that have access to a car $(78 \%)$ and have lived in their cities for 5 years or more $(97.1 \%)$. 

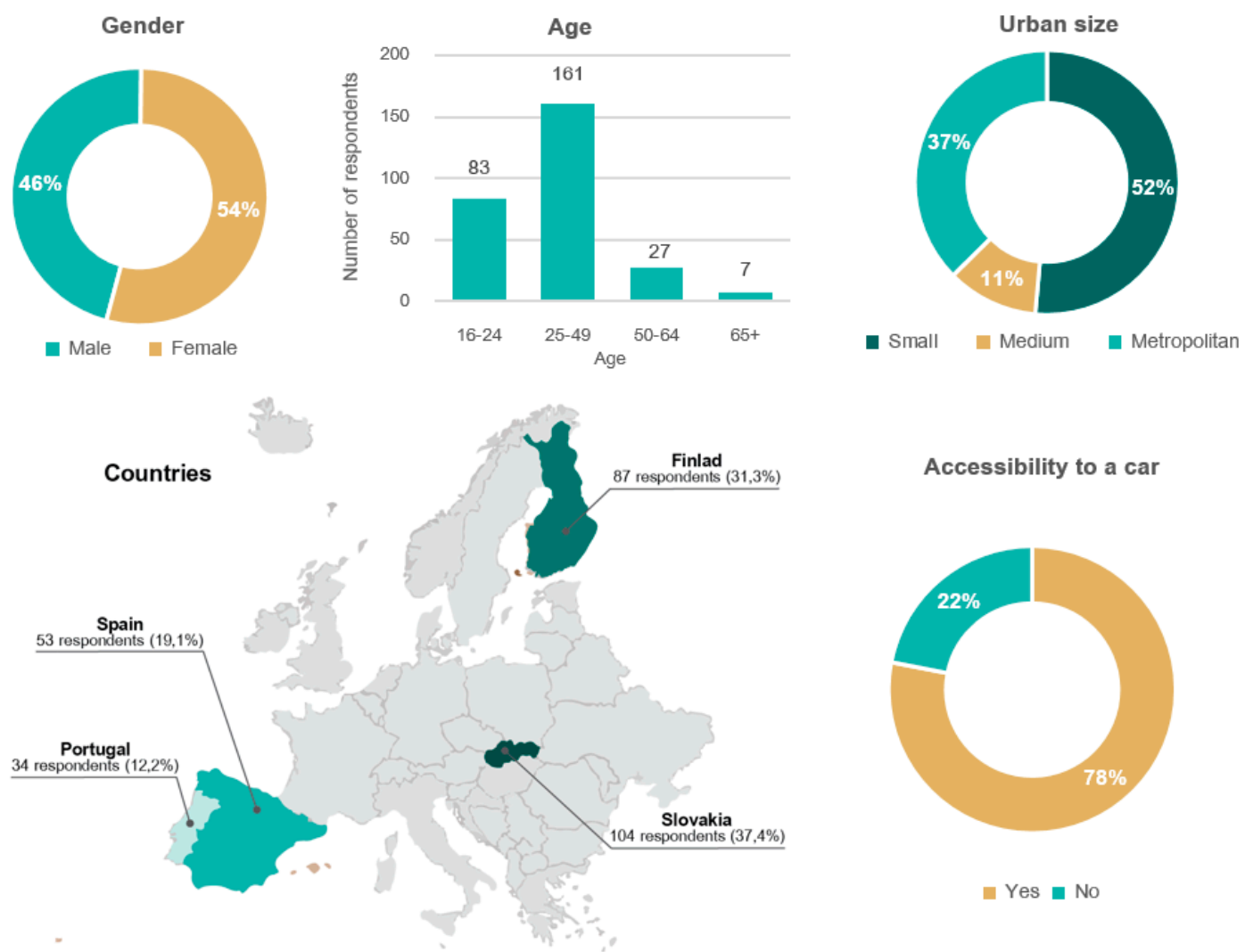

Figure 2. Socio-demographic information of respondents.

\subsection{Modeling Methodology}

Exploring people's intentions and attitudes towards ridesharing in order to determine their preference among alternatives is a complex process per se, and proper understanding of users' travel choices is essential in order to evaluate the ex ante effectiveness of possible transportation policies or services [44]. To reveal further the influence of an emerging view of VTT from the traveler's perspective based on the stated travel time worthwhileness, travelers' perception of VRS and traveler's scio-demographic charactestics on propensities in choosing different ridesharing alternatives for their daily commuting multinomial logit (MNL) model is used. The MNL is the common and most widely used discrete choice model, which is simple to formalise, assuming that the error terms are independent and identically distributed, not assuming a linear relationship between the dependent and independent variables, independent variables need not to be interval and MNL model does not require that the independents be unbounded [45]. A key disadvantage of this model is its inability to express correlation between alternatives [20]. So far, the MNL models have been applied widely in in travel behavior modeling, particularly in travel mode choice modeling due to the fact that the formula for the choice probabilities takes a closed form and is readily interpretable. The MNL model is derived through the application of utility maximization concepts to a set of alternatives from which one, the alternative with maximum utility, is chosen [44,46-49]. According to this definition, the probability of selecting alternative $i$ by individual $n$ is expressed as

$$
P_{n i}=\frac{e^{V_{n i}}}{\sum_{i=1}^{J} e^{V_{n i}}}
$$

where $P_{n i}$ is the probability that alternative $i$ is chosen by individual $n$

$e$ is the Euler's number

$V_{n i}$ is the estimate of the utility of alternative $i$ for individual $n$ 
$J$ is the number of all available alternatives.

The perceived utility of alternative $i$ by individual $n$ is derived as a linear function of explanatory variables $\left(X_{n i}\right)$ as

$$
V_{n i}=\sum_{n} \beta_{i} * X_{n i}
$$

where $\beta$ is a vector of parameters.

The perceived utility $U_{n i}^{j}$ of each traveler can be address as

$$
U_{n i}^{j}=V_{n i}^{j}+\varepsilon_{n i}^{j}
$$

where $\varepsilon_{j}^{i}$ is the random residual that represents the deviation of the utility perceived by traveler $i$ from the perceived value.

In this model five alternatives are used: (1) not interested; (2) yes, only with family and friends; (3) yes, in a taxi; (4) yes, only with someone that I know; (5) yes, even with strengers. Not interested is set as the reference alternative. Hence, as a reference alternative, the utility of 'not interested' is set to zero. It is worthwhile to mention that among the basic limitations of the research such as collection of desirable sample size, a major concern is the validity of the interpretation derived from the results obtained from the sample, and whether such interpretation can be a close approximation of the true value obtained from the target population. In our research, due to widespread geographical coverge of data collection, after screeing and cleaning the data, the sample includes 278 respondents. According to sample size guidelines a sample size around 100 and a minimum of 10 cases per independent variable would be sufficient for applying MNL model [50].

\section{Results}

\subsection{Descriptive Statistics (Data Analysis of the Factors Influencing Choice of Ridesharing)}

As it was described in literature review, the opinions of different authors regarding the impact of socio-demographic characteristics on choice of ridesharing vary. According to what is observed in our study (see Table 2$)$, only $20(7.2 \%)$ participants expressed they are not interested in sharing their rides. The rest of the participants indicated they are willing to adopt the ridesharing with friends, family or even with strangers.

From the perspective of gender balance, there is a slightly higher proportion of females then males who intent to adopt the ridesharing. Exactly 100 (36.0\%) participants expressed preference to share their rides even with strangers, while there is a negligible difference between males and females.

Considering the age of participants, the distribution of willingness to share the rides seems to be similar among different age groups. People between 16-49 tend to be more willing to share the rides with someone they know or even with strangers. Participants of age more than 50 prefer to share their rides with family or friends and less with strangers than young people which may results from perceived security and greater comfort required by older people. Considering the country of residence, the results from survey are very similar for Slovakia and Spain. In these two countries, as well as in Finland, at least $70 \%$ of participants are willing to share the rides with someone they know or even with strangers. However, people in Finland tend to be more willing to share their rides in a taxi than people in other countries. 
Table 2. Socio-demographic characteristics and intention to adopt ride sharing.

\begin{tabular}{|c|c|c|c|c|c|c|c|c|c|c|c|}
\hline \multirow{2}{*}{\multicolumn{2}{|c|}{ Variable }} & \multicolumn{2}{|c|}{$\begin{array}{c}\text { Not } \\
\text { Interested }\end{array}$} & \multicolumn{2}{|c|}{$\begin{array}{l}\text { Only with } \\
\text { Family or } \\
\text { Friends }\end{array}$} & \multicolumn{2}{|c|}{$\begin{array}{l}\text { In a } \\
\text { Taxi }\end{array}$} & \multicolumn{2}{|c|}{$\begin{array}{l}\text { With Someone } \\
\text { I Know }\end{array}$} & \multicolumn{2}{|c|}{$\begin{array}{l}\text { Even with } \\
\text { Strangers }\end{array}$} \\
\hline & & $\mathbf{n}$ & $\%$ & $\mathbf{n}$ & $\%$ & $\mathbf{n}$ & $\%$ & $\mathbf{n}$ & $\%$ & $\mathbf{n}$ & $\%$ \\
\hline \multicolumn{2}{|c|}{ Attitudes to ridesharing } & 20 & 7.2 & 52 & 18.7 & 14 & 5.0 & 92 & 33.1 & 100 & 36.0 \\
\hline \multirow{2}{*}{ Gender } & Female & 10 & 6.7 & 31 & 20.7 & 11 & 7.3 & 49 & 32.7 & 49 & 32.7 \\
\hline & Male & 10 & 7.8 & 21 & 16.4 & 3 & 2.3 & 43 & 33.6 & 51 & 39.8 \\
\hline \multirow{4}{*}{ Age } & $16-24$ & 4 & 4.8 & 15 & 18.1 & 2 & 2.4 & 32 & 38.6 & 30 & 36.1 \\
\hline & $25-49$ & 13 & 8.1 & 27 & 16.8 & 9 & 5.6 & 52 & 32.3 & 60 & 37.3 \\
\hline & $50-64$ & 2 & 7.4 & 8 & 29.6 & 3 & 11.1 & 6 & 22.2 & 8 & 29.6 \\
\hline & $65+$ & 1 & 14.3 & 2 & 28.6 & 0 & 0.0 & 2 & 28.6 & 2 & 28.6 \\
\hline \multirow{4}{*}{$\begin{array}{l}\text { Country of } \\
\text { residence }\end{array}$} & Spain & 4 & 7.5 & 10 & 18.9 & 1 & 1.9 & 16 & 30.2 & 22 & 41.5 \\
\hline & Finland & 4 & 4.6 & 12 & 13.8 & 10 & 11.5 & 30 & 34.5 & 31 & 35.6 \\
\hline & Portugal & 3 & 8.8 & 13 & 38.2 & 1 & 2.9 & 10 & 29.4 & 7 & 20.6 \\
\hline & Slovakia & 9 & 8.7 & 17 & 16.3 & 2 & 1.9 & 36 & 34.6 & 40 & 38.5 \\
\hline \multirow{3}{*}{ Urban size } & Small & 8 & 5.6 & 25 & 17.5 & 4 & 2.8 & 59 & 41.3 & 47 & 32.9 \\
\hline & Medium & 1 & 3.2 & 4 & 12.9 & 2 & 6.5 & 11 & 35.5 & 13 & 41.9 \\
\hline & Metropolitan & 11 & 10.6 & 23 & 22.1 & 8 & 7.7 & 22 & 21.2 & 40 & 38.5 \\
\hline \multirow{5}{*}{$\begin{array}{l}\text { Marital } \\
\text { status }\end{array}$} & Single & 9 & 5.5 & 27 & 16.6 & 5 & 3.1 & 56 & 34.4 & 66 & 40.5 \\
\hline & Married & 9 & 9.4 & 21 & 21.9 & 6 & 6.3 & 34 & 35.4 & 26 & 27.1 \\
\hline & Civil partnership & 2 & 18.2 & 2 & 18.2 & 1 & 9.1 & 1 & 9.1 & 5 & 45.5 \\
\hline & Divorced & 0 & 0.0 & 1 & 14.3 & 2 & 28.6 & 1 & 14.3 & 3 & 42.9 \\
\hline & Widowed & 0 & 0.0 & 1 & 100.0 & 0 & 0.0 & 0 & 0.0 & 0 & 0.0 \\
\hline \multirow{5}{*}{$\begin{array}{l}\text { Number of } \\
\text { household } \\
\text { memberes }\end{array}$} & 1 person & 0 & 0.0 & 7 & 21.9 & 2 & 6.3 & 10 & 31.3 & 13 & 40.6 \\
\hline & 2 persons & 5 & 7.4 & 7 & 10.3 & 4 & 5.9 & 21 & 30.9 & 31 & 45.6 \\
\hline & 3 persons & 8 & 13.8 & 11 & 19.0 & 3 & 5.2 & 13 & 22.4 & 23 & 39.7 \\
\hline & 4 persons & 5 & 6.8 & 18 & 24.7 & 4 & 5.5 & 29 & 39.7 & 17 & 23.3 \\
\hline & 5 persons and more & 2 & 4.3 & 9 & 19.1 & 1 & 2.1 & 19 & 40.4 & 16 & 34.0 \\
\hline \multirow{3}{*}{$\begin{array}{l}\text { Years of } \\
\text { residence }\end{array}$} & Less than a year & 0 & 0.0 & 0 & 0.0 & 0 & 0.0 & 0 & 0.0 & 2 & 100.0 \\
\hline & 1 year & 0 & 0.0 & 2 & 33.3 & 0 & 0.0 & 2 & 33.3 & 2 & 33.3 \\
\hline & 5 years and more & 20 & 7.4 & 50 & 18.5 & 14 & 5.2 & 90 & 33.3 & 96 & 35.6 \\
\hline \multirow{2}{*}{$\begin{array}{l}\text { Accessibility } \\
\text { to a car }\end{array}$} & Yes & 17 & 7.8 & 46 & 21.2 & 10 & 4.6 & 79 & 36.4 & 65 & 30.0 \\
\hline & No & 3 & 4.9 & 6 & 9.8 & 4 & 6.6 & 13 & 21.3 & 35 & 57.4 \\
\hline
\end{tabular}

More significant differences in results can be seen in case of Portugal, where $38.2 \%$ of all respondents prefer to share their rides only with family or friends comparing to $16 \%$ as an average from the other three countries. Based on the results from survey, Portuguese people seem to be more cautious when choosing a companion for ridesharing (see Figure 3).

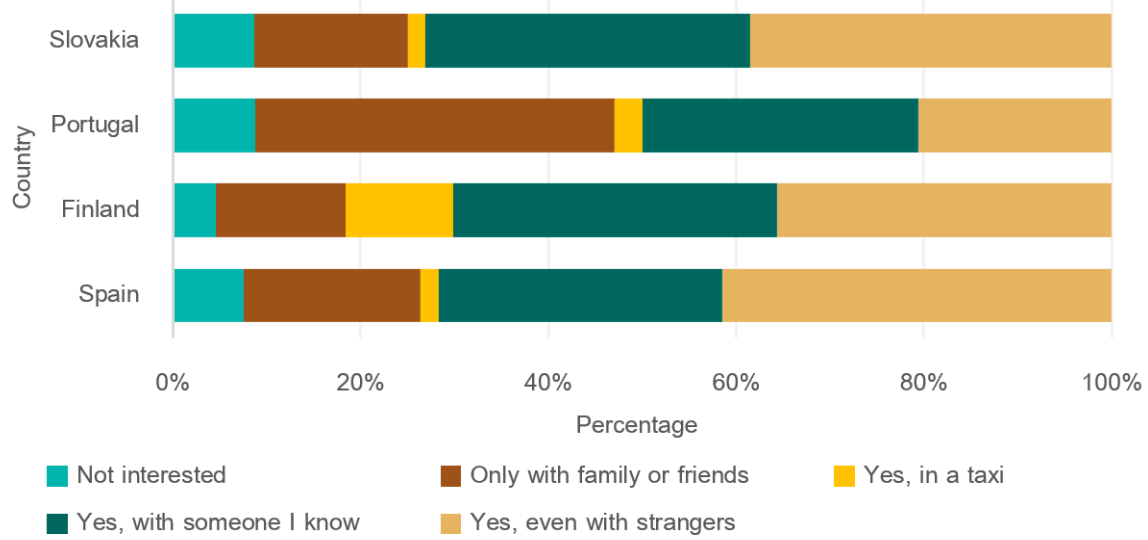

Figure 3. Intention to adopt ridesharing by country. 
When taking into account worthwhileness elements and its impact on choice of ridesharing, results (see Table 3) of the survey reveal that people who prefer enjoyment during the traveling are willing to adapt a taxi for ridesharing even with strangers.

Table 3. Elements of travel time worthwhileness perception with regard to intention to ridesharing.

\begin{tabular}{cccccccccc}
\hline \multirow{2}{*}{ Intention to Ridesharing } & \multicolumn{3}{c}{ Productivity } & \multicolumn{3}{c}{ Enjoyment } & \multicolumn{3}{c}{ Health } \\
\cline { 2 - 9 } & Mean & Median & $\begin{array}{c}\text { Std. } \\
\text { Dev. }\end{array}$ & Mean & Median & $\begin{array}{c}\text { St. } \\
\text { Dev. }\end{array}$ & Mean & Median & $\begin{array}{c}\text { Std. } \\
\text { Dev. }\end{array}$ \\
\hline All & 48.70 & 50 & 27.988 & 70.53 & 74 & 24.480 & 54.28 & 50 & 27.160 \\
Not interested & 43.90 & 50 & 28.503 & 62.35 & 56 & 25.757 & 48.55 & 50 & 30.064 \\
Only with family or friends & 46.77 & 50 & 28.086 & 72.35 & 80 & 22.109 & 46.37 & 50 & 26.470 \\
Yes, in a taxi & 44.50 & 50 & 26.287 & 66.21 & 66 & 19.993 & 54.21 & 50 & 24.360 \\
With someone that I know & 47.86 & 50 & 27.615 & 68.63 & 70 & 21.139 & 54.59 & 50 & 23.709 \\
Even with strangers & 52.03 & 50 & 28.526 & 73.57 & 79 & 20.445 & 59.28 & 58 & 29.496 \\
\hline
\end{tabular}

The results of the survey demonstrate that most people prefer to adopt ridesharing for work compared to other trip purposes. In this case, $41(21 \%)$ of all respondents are willing to share their rides only with family or friends and 72 (36\%) of respondents are willing to adopt ridesharing when commuting to/from work even with strangers. People prefer to share the rides for the purpose of hobby or leisure during the weekend. Only $21 \%$ of respondents are willing to adopt ridesharing during evening trips which may be due to the perception of reduced safety mainly by women (Figure 4).

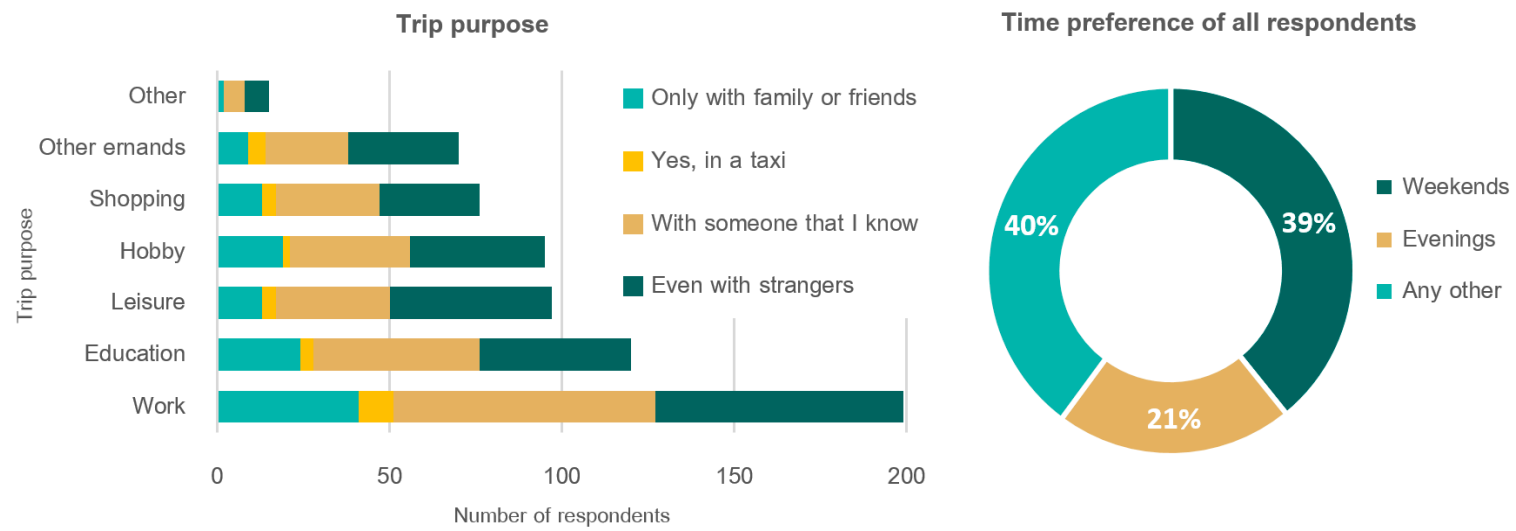

Figure 4. Trip purpose and time preference to adopt ridesharing.

To increase interest in ridesharing, it is necessary to identify the main motivators. The aggregate results (Figure 5) show that the biggest motivator for respondents to share a ride is cost saving or financial benefit (35\%). The other two important motivators are easier travel $(24 \%)$ and helping the environment (22\%) which belongs to the most frequently chosen reasons for the use of this type of transportation also in Switzerland [22] and France [25].

If we compare results based on categories of ridesharing intention, cost savings or financial benefit was not in the first place only in category "only with family or friends". In this category easier travel was identified as the major motivator. This can be caused by better communication when traveling with the family or friends, which also means better adoptation to the conditions of the passengers.

The adoptation to the conditions of the passengers is also related to the acceptance of the travel time increase. Based on the results (Figure 5), most respondents accept an increase in travel time of up to $5 \mathrm{~min}$. Concerning the intention to share a ride, no significant differences in respondents' views on travel time increase were identified. 

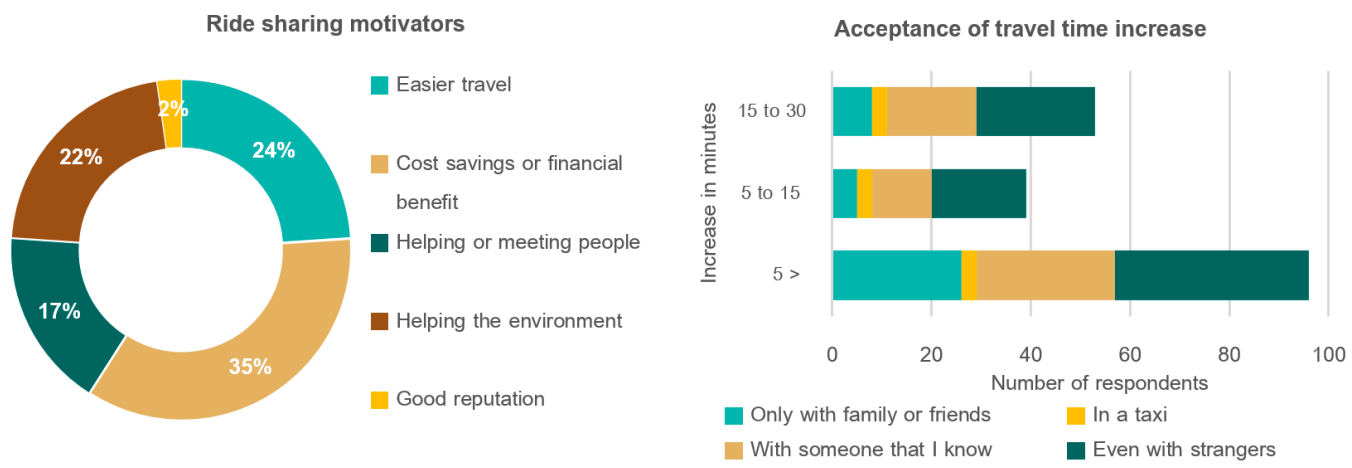

Figure 5. Motivators and acceptance of increasing travel time in ridesharing.

\subsection{Analysis of Differences in Individuals' Intentions Towards Ridesharing in Four EU Countries}

Ridesharing participation intention data of people over the age of 16 was analysed using MNL regression in SPSS23 that is appropriate when the outcome variables are categorical with more than two categories and the predictors are of any type. The ridesharing choice model was estimated by using the maximum likelihood method. The results after modification according to final model represent that our model was fitted well (see Table 4). The pseudo R-square indices in multinomial logistic regression is treated as $R^{2}$. Pseudo R-square values can reach to a maximum of 1 and larger that indicate more of the variation is explained by the model.

Table 4. Pseudo R-square measures for estimation of probabilities of ridesharing choice model.

\begin{tabular}{cc}
\hline Pseudo R-Square & Measures \\
\hline Cox and Snell & 0.572 \\
Nagelkerke & 0.610 \\
McFadden & 0.305 \\
\hline
\end{tabular}

Estimation results of MNL are presented in Table 5. The Table 5 shows parameter values, and significants with respect to the intention of respondents to adopt ridesharing. Based on the results, the significant parameters in the willingness to share rides with somebody that people know are living in medium city, trip purpose (work), and time period (weekends and evenings). Factors such as trip purpose (work or hobby/sport), the perceived value of ridesharing (help/meet someone) and time period have been identified for sharing a ride in a taxi.

Table 5. Multinomial ridesharing choice model estimation in the participant countries-intention to adopt ridesharing.

\begin{tabular}{ccccccccc}
\hline Intention to Adopt Ridesharing: & $\begin{array}{c}\text { Only with Family or } \\
\text { Friends }\end{array}$ & \multicolumn{2}{c}{ Yes, in a Taxi } & \multicolumn{2}{c}{$\begin{array}{c}\text { Yes, with Someone } \\
\text { that I Know }\end{array}$} & \multicolumn{2}{c}{$\begin{array}{c}\text { Yes, Even with } \\
\text { Strangers }\end{array}$} \\
\hline Explantory Varibles & B & Sig. & B & Sig. & B & Sig. & B & Sig. \\
\hline Gender (dummy) & & & & & & & & \\
Female = & -0.060 & 0.95 & -0.48 & 0.73 & 0.59 & 0.51 & 0.84 & 0.38 \\
Female = & 0 & & 0 & & 0 & & 0 & \\
\hline Age (dummy) & & & & & & & & \\
Age group (16-24) & 1.32 & 0.62 & 13.04 & 0.99 & 2.49 & 0.39 & 2.90 & 0.32 \\
Age group (25-49) & -2.42 & 0.32 & 11.09 & 0.99 & -1.41 & 0.59 & -0.75 & 0.77 \\
Age group (50-64) & -0.89 & 0.71 & 14.45 & 0.98 & -0.19 & 0.94 & 0.034 & 0.99 \\
Age group (65+) & 0 & & 0 & & 0 & & 0 & \\
\hline
\end{tabular}


Table 5. Cont.

\begin{tabular}{|c|c|c|c|c|c|c|c|c|}
\hline \multirow{2}{*}{$\begin{array}{c}\text { Intention to Adopt Ridesharing: } \\
\text { Explantory Varibles }\end{array}$} & \multicolumn{2}{|c|}{$\begin{array}{l}\text { Only with Family or } \\
\text { Friends }\end{array}$} & \multicolumn{2}{|c|}{ Yes, in a Taxi } & \multicolumn{2}{|c|}{$\begin{array}{l}\text { Yes, with Someone } \\
\text { that I Know }\end{array}$} & \multicolumn{2}{|c|}{$\begin{array}{l}\text { Yes, Even with } \\
\text { Strangers }\end{array}$} \\
\hline & B & Sig. & B & Sig. & B & Sig. & B & Sig. \\
\hline \multicolumn{9}{|l|}{$\begin{array}{l}\text { Number of household members } \\
\text { (dummy) }\end{array}$} \\
\hline N.HH. members (1) & 9.60 & 0.97 & 8.65 & 0.97 & 8.81 & 0.97 & 9.57 & 0.97 \\
\hline N.HH. members (2) & -3.23 & 0.04 & -1.95 & 0.39 & -2.80 & 0.08 & -2.51 & 0.12 \\
\hline N.HH. members (3) & -4.28 & 0.01 & -3.48 & 0.16 & -4.67 & 0.00 & -4.00 & 0.02 \\
\hline N.HH. members (4) & -2.21 & 0.18 & -0.83 & 0.71 & -2.47 & 0.13 & -3.06 & 0.06 \\
\hline N.HH. members (5 and more) & 0 & & 0 & & 0 & & 0 & \\
\hline \multicolumn{9}{|l|}{ Urban size (dummy) } \\
\hline Small size & -0.91 & 0.55 & -2.94 & 0.09 & 0.128 & 0.93 & -1.71 & 0.25 \\
\hline Medium size & 4.14 & 0.05 & 1.19 & 0.64 & 5.13 & 0.01 & 4.64 & 0.02 \\
\hline Metropolitan & 0 & & 0 & & 0 & & 0 & \\
\hline \multicolumn{9}{|l|}{ Country of residence (dummy) } \\
\hline Spain & 1.29 & 0.47 & -2.57 & 0.33 & 1.81 & 0.31 & 0.54 & 0.75 \\
\hline Finland & 2.52 & 0.13 & 4.15 & 0.03 & 2.80 & 0.09 & 1.82 & 0.26 \\
\hline Portugal & 1.91 & 0.28 & -1.43 & 0.57 & 2.36 & 0.19 & -0.135 & 0.94 \\
\hline Slovakia & 0 & & 0 & & 0 & & 0 & \\
\hline Years of residence & -11.61 & 0.00 & -2.10 & 0.99 & -11.34 & 0.000 & -12.09 & \\
\hline \multicolumn{9}{|l|}{ Perceived value of travel time } \\
\hline Productivity value & -0.008 & 0.69 & -0.041 & 0.11 & -0.008 & 0.68 & -0.008 & 0.67 \\
\hline Enjoyment value & 0.074 & 0.00 & 0.089 & 0.00 & 0.068 & 0.0 & 0.082 & 0.00 \\
\hline Fitness value & -0.030 & 0.08 & -0.001 & 0.95 & -0.015 & 0.39 & -0.011 & 0.54 \\
\hline \multicolumn{9}{|l|}{ Trip purpose (dummy) } \\
\hline Work trip & 3.66 & 0.03 & 3.83 & 0.04 & 4.32 & 0.01 & 3.74 & 0.02 \\
\hline Education trip & 2.56 & 0.08 & 1.94 & 0.28 & 2.49 & 0.09 & 2.58 & 0.09 \\
\hline Shopping trip & 0.75 & 0.68 & 2.07 & 0.31 & 1.56 & 0.39 & 1.36 & 0.45 \\
\hline Hobby/Sport trip & -0.90 & 0.51 & -5.16 & 0.00 & -1.66 & 0.23 & -1.75 & 0.20 \\
\hline Leisure trip & 0.33 & 0.83 & -0.60 & 0.75 & 0.19 & 0.90 & 0.29 & 0.856 \\
\hline \multicolumn{9}{|l|}{ Time period } \\
\hline Weekends & 4.87 & 0.00 & 5.93 & 0.00 & 4.78 & 0.007 & 5.69 & 0.001 \\
\hline Evenings & 4.34 & 0.04 & 5.73 & 0.01 & 5.60 & 0.007 & 5.01 & 0.016 \\
\hline Any other time & 5.41 & 0.013 & 9.11 & 0.00 & 6.38 & 0.003 & 6.07 & 0.005 \\
\hline \multicolumn{9}{|l|}{$\begin{array}{l}\text { Perceived value of ridesharing } \\
\text { (dummy) }\end{array}$} \\
\hline Easier travel & 0.69 & 0.45 & -0.61 & 0.63 & 0.80 & 0.39 & 0.22 & 0.80 \\
\hline Economic benefit & 0.94 & 0.43 & -0.88 & 0.58 & 2.25 & 0.05 & 1.99 & 0.09 \\
\hline Help/meet & -1.93 & 0.28 & -4.11 & 0.05 & -2.02 & 0.26 & -1.71 & 0.34 \\
\hline Environment concerns & 1.46 & 0.32 & 2.57 & 0.13 & 0.73 & 0.61 & 1.55 & 0.28 \\
\hline Good reputation & 6.64 & 0.98 & -4.17 & 0.99 & 6.48 & 0.98 & 7.43 & 0.98 \\
\hline \multicolumn{9}{|l|}{$\begin{array}{l}\text { Acceptable travel time increase } \\
\text { (dummy) }\end{array}$} \\
\hline $5 \mathrm{~min}$ or less & 0.083 & 0.94 & -0.86 & 0.55 & 6.48 & 0.98 & 7.43 & 0.88 \\
\hline 5 to $15 \mathrm{~min}$ & 4.29 & 0.98 & 11.71 & 0.96 & -0.66 & 0.55 & 0.16 & 0.98 \\
\hline 15 to $30 \mathrm{~min}$ & 7.15 & 0.05 & 1.39 & 0.80 & 3.91 & 0.98 & 4.04 & 0.04 \\
\hline
\end{tabular}

The reference category is 'not interested'.

\section{Discussion}

The estimated results reveal the significant effects of used variables on ridesharing choice vs. driving alone which are discussed in following sub-sections.

\subsection{Effects of Exogenous Factors}

The influences from socio-demographic and built environment variables on people's intention towards choosing ridesharing options are alluded in this section. According to preceding studies [51-54], socio-demographic characteristics play a minor role in ridesharing schemes such as carpooling and car sharing. While Prieto et al. [14] found the socio demographic variables as an important actor in charge of changing people behavior regarding car sharing services. As can be seen below, we found 
out that household size (i.e., number of household members), urban size and years of residence were the strongest influencers on respondents' intention towards ridesharing choice that is consistent with Efthymiou et al. [55].

1. Gender: with regards to individuals' characteristics, being female was not a significant predictor to participate in available ridesharing options.

2. Age: respondents age, as we expected, was not significant predictor for choosing ridesharing. For instance, multinomial log-odds of people in age range of 16-24 years is 2.99 unit higher for preferring to choose ridesharing with strangers given other ridesharing choices which means youths in participant countries are more likely to prefer to share a ride with someone they know or even a stranger compared to having the possibility to share a ride with family members.

3. Household size: the results demonstrate that household size has a negative significant impact on choosing ridesharing with family members and others. Results indicate that people from households with three persons tend to select less ridesharing with someone they already know compared to other ridesharing choices such as with family members and even strangers.

4. Urban size: the built environment and residing in medium city is significant predictor for being interested in shared rides with others. According to the results, it can be interpreted that people in medium cities, compared to small and metropolitan cities citizens, are more likely willing to participate in a ridesharing with someone they know.

5. Country of residence: the country of residence as a categorical variable was modeled for four groups of citizens in Spain, Finland, Portugal, and Slovakia. Based on the results, it can be interpreted that residence location has no significant impact on participation in ridesharing with family members and someone that respondents already know. On the other hand, analysis results reveal a high tendency of sharing a taxi among Finnish people compared to Spanish, Portuguese, and Slovak citizens.

6. Years of residence: respondents' years of residence in the participant countries has a negative significant impact on their intention to use ridesharing with family or friends and someone they know compared to those people who would probably be willing for sharing ride with strangers. It means people with increasing their years of residency will more likely be less interested to share ride with family members or friends.

\subsection{Effects of Endogenous Factors}

The impacts from travel-related variables on people's intention towards choosing ridesharing options are discussed in this section. It should be noted that some recent studies $[46,56,57]$ highlighted the influence of perceptions (e.g., sustainability concerns, sociability, altruism, interpersonal rapport) on ridesharing participation intention that are partially consistent with our obtained results.

1. Trip purpose: obtained results reveal that among the trip purposes associated to people's preference for ridesharing, work trip has a positive impact on sharing a ride. This demonstrates that work trip purpose has the highest propensity among people for sharing rides with family and friends and even strangers compared to those people who showed that thay are not interested in participating in any type of ridesharing.

2. Time of day: according to the results, the most preferred time periods for shared rides with family and friends are weekends and mornings of working days. When it comes to sharing a taxi or a ride with someone they know results show that people are willing to share rides any time during weekdays and weekends. Concerning ridesharing with strangers, results also indicate that high tendency among people for useing ridesharing is during weekends.

3. Perceived value of travel time: among three core values of users' perception of travel time worthwhileness, enjoyment value has a positive significant influence on individuals' preference for choosing ridesharing for daily commuting. Results reveal that those people who have higher 
expectation of enjoyment during travel time are more likely to use a taxi for ridesharing even with strangers.

4. Perceived value of ridesharing: regarding individuals' expected value of ridesharing, it can be figured out from the results that helping and meeting people (i.e., enjoyment of being social) is a significant motivation for respondents to choose a taxi for ridesharing which is consistent with Burkhardt and Millard-Ball [58] findings.

5. Acceptable TT increase: according to the results, people who are interested in participating in ridesharing options are expecting more likely an increase of 15-30 min in their travel time, in particular when they tend to share a ride with someone they know.

In a nutshell, our research hints on the need to explore broader meanings of ridesharing to assign to the concept of value of travel time and value of ridesharing to peer-to-peer (P2P) shared mobility planning. The main conclusion derived from this study is the complexity of people behavior and subjective attitudes influencing ridesharing choice. In short, the empirical analysis indicates the high significance of enjoyment in terms of travel time worthwhileness on ridesharing adoption for their commuting trips. It means as long as people are happy/satisfied for the time spent on transport they can tolerate an increase of travel time from 15 to $30 \mathrm{~min}$.

To further elaborate on this, findings from this study prove that the decision to rideshare with family or friends are driven by youths in the age range of 16-24 years in households consisting of two persons who are long-time residents in medium-sized cities. Results also reveal that people with the same preference are more open to share a ride for work trips that could probably increase their travel time from 15 to $30 \mathrm{~min}$. People in this group would also expect to experience an enjoyable travel time.

Regarding the respondents who have a higher perceived utility of taxi sharing, our analysis demonstrates that people in this group are interested in joining a ridesharing for work and hobby/sport trips. Then it can be interpreted that the main reason for these people is social-hedonic motives (e.g., meeting people, help). Interestingly, Finnish people are more likely to choose sharing a taxi with others compared with other European citizens in Spain, Portugal, and Slovakia any time during weekdays and weekends. Our results also reveal that in case of people who are willing to join ridesharing with someone they already know, the motivational factor behind this decision will be economic benefits (e.g., cost saving, financial benefit). Household size and long-time residents in medium-sized cities are also major determinates of this type of ridesharing choice among respondents' other alternatives.

Finally, the results indicate the same signficance factors such as perceived enjoyment value of travel time, acceptance of 15-30 min of travel time increase, work trip purpose and workday and weekends as preferred times for ridesharing on people's intention to share a ride with someone that they know or have met before.

\section{Conclusions}

Value proposition of mobility (VPM) is a perspective on value of travel time that focuses on the "promise of value to be delivered, communicated, and acknowledged to the individual traveler". This means that the value proposition of mobility is the subjective, dynamic, and contextual valuation of available (or preferred) mobility options. Therefore, VPM as the value embedded in individual mobility choices implies a range of expectations associated to mobility behavior which are tightly connected to motivational factors. Although many studies have been conducted to broaden the scope of ridesharing in transport planning and policies in the EU and national frameworks, there has been little attention to explore simultaneously the influence of hedonic and eudaimonic values in travel time and ridesharing, gender, generational cohort, and built environment on individuals' intention for participation in ridesharing as part of travel behavior. As perceived quality of time influences individual well-being [59], it is important to understand and reflect on one's own time use, for instance to adjust one's own behavior and to consider alternative choices that would better fulfil travelers' needs, goals, and expectations. Therefore, the objective of this paper was to investigate main determinants 
of the ridesharing choice behavior while assessing how users' perception of value of travel time (VTT) in connection with cultural and social contexts affects travelers' behavioral willingness to adopt ridesharing for their daily trips.

Findings from this study are also supposed to provide an evidence-based support and in-depth understanding of effective factors such as perception of VTT in decision-making process about travel mode choice (i.e., ridesharing). These findings could have important implications for urban and transport planners, policy makers, and authorities to implement more user-centric designs in urban mobility plans and to prepare inclusive transport policies which tailored to individuals' needs and travel preferences considering ridesharing services (carpooling, car sharing, crowed sourced micro-task deliveries). Hence, the results can be used as inputs to three broader discussions with implications to transport policy-making and planning: (1) guiding people's acceptance and use of ridesharing in particular peer-to-peer (P2P) car sharing; (2) the use of ridesharing as tool for being more social and having a higher level of enjoyment; (3) and enabling P2P delivery system by NGOs and start-ups for goods in which anyone can request a delivery or become a transporter.

Further research is required to evaluate the effects of integrating users' assessment of the travel experience (i.e., revealed experience) across transport modes while on move thanks to a European-wide mobility and behavioral pattern dataset collected through Woorti App during the H2020 MoTiV Project. Our future research focus will be to analyse the perceived value of travel time and associated experience factors to assess their overall impact on using ridesharing services and participation in the application of crowdsourcing in the mobility context to demonstrate how changing people attitudes and travel behavior, not only based on the cost-time paradigm but also on personal value propositions in the direction of sustainable and smart transport management could be affected by such a system. Crowdsourced micro-tasks as an activity and application area shifting away from the 'speed paradigm' with a significant impact on VTT will also be analysed to determine whether the gained knowledge on users' perception of VTT will be a significant predictor on future expectations of city-dwellers and surging ridesharing services in urban areas. This analysis will benefit from the experience gained in this area by CoReorient, the MoTiV project partner that developed PiggyBaggy, a system enabling convenient, low cost, sustainable, and secure crowdsourced door-to-door delivery of small goods.

Author Contributions: Conceptualization, G.P. and E.M.; Methodology, G.P.; Software, G.P.; Formal analysis, G.P., E.M., and M.H.; Investigation, E.M. and G.P.; Data curation, G.P.; Writing-original draft preparation, E.M., G.P., and M.H.; Writing-review and editing, G.P., E.M., M.H., and T.K.; Visualization, E.M.; Supervision, G.P. All authors have read and agreed to the published version of the manuscript.

Funding: This research received funding from the European Union's Horizon 2020 research and innovation programme under grant agreement no. 770145

Acknowledgments: The authors would like to thank the MoTiV partners who significantly contributed to the ridesharing survey of this paper: Heikki Warris, Harri Paloheimo-CoReorient (Finland), Ludovico Boratto, Marina Presas Quintana-Eurecat (Spain), Fatima Santos and Andre Freitas-TIS (Portugal).

Conflicts of Interest: The authors declare no conflict of interest. The funders had no role in the design of the study; in the collection, analyses, or interpretation of data; in the writing of the manuscript, or in the decision to publish the results.

\section{References}

1. Rong, K.; Xiao, F.; Wang, Y. Redundancy in the sharing economy. Resour. Conserv. Recycl. 2019, 151, 104455. [CrossRef]

2. Yuana, S.L.; Sengers, F.; Boon, W.; Raven, R. Framing the sharing economy: A media analysis of ridesharing platforms in Indonesia and the Philippines. J. Clean. Prod. 2019, 212, 1154-1165. [CrossRef]

3. The Use of the Collaborative Economy 2018. Available online: https://op.europa.eu/en/publication-detail/-/ publication/34eb3c1f-cb6f-11e8-9424-01aa75ed71a1 (accessed on 14 January 2020).

4. Machado, C.A.S.; Hue, N.P.M.; Berssaneti, F.T.; Quintanilha, J.A. An overview of shared mobility. Sustainability 2018, 10, 4342. [CrossRef] 
5. Shared Mobility Definitions. Available online: https://www.transit.dot.gov/regulations-and-guidance/ shared-mobility-definitions (accessed on 14 January 2020).

6. Jiao, J.; Bischak, C.; Hyden, S. The impact of shared mobility on trip generation behavior in the US: Findings from the 2017 national household travel survey. Travel Behav. Soc. 2020, 19, 1-7. [CrossRef]

7. Eurostat: Passenger Cars in the EU. Available online: https://ec.europa.eu/eurostat/statistics-explained/index. php?title=Passenger_cars_in_the_EU\&oldid=438653\#Overview (accessed on 14 January 2020).

8. Deloitte: The Rise of the Sharing Economy. Available online: https://www2.deloitte.com/content/ dam/Deloitte/us/Documents/consumer-business/us-cb-the-rise-the-sharing-economy.pdf (accessed on 14 January 2020).

9. Delitheou, V.; Bakogiannis, E.; Kyriakidis, C. Urban planning: Integrating smart applications to promote community engagement. Heliyon 2019, 5, e01672. [CrossRef]

10. Attard, M.; Haklay, M.; Capineri, C. The potential of Volunteered Geographic Information (VGI) in future transport systems. Urban Planing 2016, 1, 6-19. [CrossRef]

11. Kováčiková, T.; Lugano, G.; Pourhashem, G. From travel time and cost savings to value of mobility. In Proceedings of the 17th International Multi-Conference "Reliability and Statistics in Transportation and Communication" (RelStat 2017), Riga, Latvia, 18-21 October 2017; pp. 35-43.

12. Lugano, G.; Kurillova, Z.; Hudák, M.; Pourhashem, G. Beyond travel time savings: Conceptualizing and modelling the individual value proposition of mobility. In Proceedings of the 4 th Conference on Sustainable Urban Mobility, Skiathos Island, Greece, 24-25 May 2018.

13. Wang, Y.; Gu, J.; Wang, S.; Wang, J. Understanding consumers' willingness to use ride-sharing services: The roles of perceived value and perceived risk. Transp. Res. Part C Emerg. Technol. 2019, 105, 504-519. [CrossRef]

14. Prieto, M.; Baltas, G.; Stan, V. Car sharing adoption intention in urban areas: What are the key, sociodemographic drivers? Transp. Res. Part A Policy Pract. 2017, 101, 218-227. [CrossRef]

15. Ballus-Armet, I.; Shaheen, S.; Clonts, K.; Weinzimmer, D. Peer-to-peer carsharing: Exploring public perception and market characteristics in the San Francisco Bay Area. Transp. Res. Rec. J. Transp. Res. 2014, 2416, 27-36. [CrossRef]

16. Payyanadan, R.P.; Lee, J.D. Understanding the ridesharing needs of older adults. Travel Behav. Soc. 2018, 13, 155-164. [CrossRef]

17. Amirkiaee, S.Y.; Evangelopoulos, N. Why do people rideshare? An experimental study. Transp. Res. Part F Traffic Psychol. Behav. 2018, 55, 9-24. [CrossRef]

18. Cheyne, C.; Imran, M. Shared transport: Reducing energy demand and enhancing transport options for residents of small towns. Energy Res. Soc. Sci. 2016, 18, 139-150. [CrossRef]

19. TCRP Research Report: Shared Mobility and the Transformation of Public Transit. Available online: http://www.trb.org/Main/Blurbs/174653.aspx (accessed on 14 January 2020).

20. Bahat, O.; Bekhor, S. Incorporating ridesharing in the static traffic assignment model. Netw. Spat. Econ. 2016, 16, 1125-1149. [CrossRef]

21. Ciari, F. Why do people carpool? Results from a Swiss survey. In Proceedings of the Swiss Transport Research Conference, Monte Verità, Ascona, Switzerland, 2-4 May 2012.

22. Wang, Y.; Winter, S.; Tomko, M. Collaborative activity-based ridesharing. J. Transp. Geogr. 2018, 72, $131-138$. [CrossRef]

23. Arbour-Nicitopoulos, K.; Faulkner, G.E.J.; Buliung, R.N.; Lay, J.; Stone, M. The school run: Exploring carpooling as an intervention option in the Greater Toronto and Hamilton Area (GTHA), Canada. Transp. Policy 2012, 21, 134-140. [CrossRef]

24. Delhomme, P.; Gheorghiu, A. Comparing French carpoolers and non-carpoolers: Which factors contribute the most to carpooling? Transp. Res. Part D Transp. Environ. 2016, 42, 1-15. [CrossRef]

25. Li, J.; Embry, P.; Mattingly, S.P.; Sadabadi, K.F.; Rasmidatta, I.; Burris, M.W. Who Chooses to Carpool and Why? Examination of Texas Carpoolers. Transp. Res. Rec. J. Transp. Res. Board 2007, 2021, 110-117. [CrossRef]

26. Vanoutrive, T.; Van De Vijver, E.; Van Malderen, L.; Jourquin, B.; Thomas, I.; Verhetsel, A.; Witlox, F. What determines carpooling to workplaces in Belgium: Location, organisation or promotion? J. Transp. Geogr. 2012, 22, 77-86. [CrossRef]

27. Cervero, R. Paratransit in America: Redefining Mass Transportation; Green-wood Publishing Group: Westport, CT, USA, 1997. 
28. Rayle, L.; Dai, D.; Chan, N.; Cerveo, R.; Shaheen, S. Just a better taxi? A survey-based comparison of taxis, transit, and ridesourcing services in San Francisco. Transp. Policy 2016, 45, 168-178. [CrossRef]

29. Contreras, S.D.; Paz, A. The effects of ride-hailing companies on the taxicab industry in Las Vegas, Nevada. Transp. Res. Part A 2018, 115, 63-70. [CrossRef]

30. Caulfield, B. Estimating the environmental benefits of ride-sharing: A case study of Dublin. Transp. Res. Part D 2009, 14, 527-531. [CrossRef]

31. Ma, R.; Zhang, H.M. The morning commute problem with ridesharing and dynamic parking charges. Transp. Res. Part B Methodol. 2017, 106, 345-374. [CrossRef]

32. Hartman, I.B.; Keren, D.; Dbai, A.A.; Cohen, E.; Knapen, L.; Yasar, A.; Janssens, D. Theory and practice in large carpooling problems. Procedia Comput. Sci. 2014, 32, 339-347. [CrossRef]

33. Van der Waerden, P.; Lem, A.; Schaefer, W. Investigation of factors that stimulate car drivers to change from car to carpooling in city center oriented work trips. Transp. Res. Procedia 2015, 10, 335-344. [CrossRef]

34. Li, R.; Liu, Z.; Zhang, R. Studying the benefits of carpooling in an urban area using automatic vehicle identification data. Transp. Res. Part C Emerg. Technol. 2018, 93, 367-380. [CrossRef]

35. Ou, H.; Tang, T.Q. Impacts of carpooling on trip costs under car-following model. Phys. A Stat. Mech. Appl. 2018, 505, 136-143. [CrossRef]

36. Yu, B.; Ma, Y.; Xue, M.; Tang, B.; Wang, B.; Yan, J.; Wei, M. Environmental benefits from ridesharing: A case of Beijing. Appl. Energy 2017, 191, 141-152. [CrossRef]

37. Bachmann, F.; Hanimann, A.; Artho, J.; Jonas, K. What drives people to carpool? Explaining carpooling intention from the perspectives of carpooling passengers and drivers. Transp. Res. Part F Traffic Psychol. Behav. 2018, 59, 206-268. [CrossRef]

38. Bulteau, J.; Feuillet, T.; Dantan, S. Carpooling and carsharing for commuting in the Paris region: A comprehensive exploration of the individual and contextual correlates of their uses. Travel Behav. Soc. 2019, 16, 77-87. [CrossRef]

39. Neoh, J.G.; Chipulu, M.; Marshall, A. What encourages people to carpool? An evaluation of factors withmeta-analysis. Transportation 2017, 44, 423-447. [CrossRef]

40. Olsson, L.E.; Maier, R.; Friman, M. Why do they ride with others? Meta-analysis of factors influencing travelers to carpool. Sustainability 2019, 11, 2414. [CrossRef]

41. Zhang, Y.; Zhang, Y. Examining the relationship between household vehicle ownership and ridesharing behaviors in the United States. Sustainability 2018, 10, 2720. [CrossRef]

42. Neoh, G.; Chipulu, M.; Marshall, A.; Tewkesbury, A. How commuters' motivations to drive relate to propensity to carpool: Evidence from the United Kingdom and the United States. Transp. Res. Part A Policy Pract. 2018, 110, 128-148. [CrossRef]

43. Chaube, V.; Kavanaugh, A.L.; Perez-Quinones, M.A. Leveraging social networks to embed trust in rideshare programs. In Proceedings of the 43rd Hawaii International Conference on System Sciences, Honolulu, HI, USA, 5-8 January 2010; pp. 1-8.

44. Birgillito, G.; Rindone, C.; Vitetta, A. Passenger mobility in a discontinuous space: Modelling access/egress to maritime barrier in a case. J. Adv.Transp. 2018, 2018, 1-13. [CrossRef]

45. Tabachnick, B.G.; Fidell, L.S.; Osterlind, S.J. Using Multivariate Statistics; Pearsons: New York, NY, USA, 2001.

46. Koppelman, F.S.; Sethi, V. Closed-form discrete-choice models. In Hand Book Transport Modeling; Hensher, D.A., Button, K.J., Eds.; Elsevier Science Ltd.: Amsterdam, The Netherlands, 2000; pp. 211-227.

47. Ben-Akiva, M.; Bierlaire, M. Discrete choice methods and their applications to short term travel decisions. In Handbook of Transportation Science. International Series in Operations Research \& Management Science; Springer: Boston, MA, USA, 1999; Volume 23.

48. Ben-Akiva, M.; Lerman, S.R. Discrete Choice Analysis Theory and Application to Travel Demand; MIT Press: Cambridge, UK, 1985.

49. Cascetta, E. Travel-demand Models' in Panos. In Transportation Systems Analysis: Models and Applications; Pardalos, M., Du, D.-Z., Eds.; Springer: Berlin/Heidelberg, Germany, 2009.

50. Schwab, J.A. Multinomial Logistic Regression: Basic Relationships and Complete Problems; The University of Texas in Austin: Austin, TX, USA, 2002.

51. Lee, B.H.-Y.; Aultman-Hall, L.; Coogan, M.; Adler, T. Rideshare mode potential in non-metropolitan areas of the northeastern United States. J. Transp. Land Use 2015, 9. [CrossRef] 
52. Silvis, J.; Niemeier, D. Social network and dwelling characteristics that influence ridesharing behavior of seniors. Transp. Res. Rec. 2009, 2118, 47-54. [CrossRef]

53. Kaufman, S. Why people (don't) carpool and change for the better. In Proceedings of the Second International Conference on Sustainable Campuses, Melbourne, Australia, 2-4 October 2002.

54. Hartgen, D. Ridesharing Behavior: A Review of Recent Findings; Preliminary Research Report 130; New York State Department of Transportation: Albany, NY, USA, 1977.

55. Efthymiou, D.; Antoniou, C.; Waddell, P. Factore affecting the adoption of vehicle sharing systems by young drivers. Transp. Policy 2013, 29, 64-73. [CrossRef]

56. Bucher, E.; Fieseler, C.; Lutz, C. What's mine is yours (for a nominal fee)-Exploring the spectrum of utilitarian to altruistic motives for Internetmediated sharing. Comput. Hum. Behav. 2016, 62, 316-326. [CrossRef]

57. Shumaker, S.A.; Brownell, A. Toward a theory of social support: Closing conceptual gaps. J. Soc. Issues 1894, 40, 11-36. [CrossRef]

58. Burkhardt, J.; Millard-Ball, A. Who is attracted to carsharing? Transp. Res. Rec. J. Transp. Res. Board 2006, 98-105. [CrossRef]

59. Mogilner, C.; Norton, M.I. Time, money, and happiness. Curr. Opin. Psychol. 2016, 10, 12-16. [CrossRef]

(C) 2020 by the authors. Licensee MDPI, Basel, Switzerland. This article is an open access article distributed under the terms and conditions of the Creative Commons Attribution (CC BY) license (http://creativecommons.org/licenses/by/4.0/). 